\title{
POSIÇÕES SUJEITO ENTRE MARCAS, TRAÇOS, LÍNGUAS...
}

\author{
SUBJECT POSITIONS AMONG MARKS, TRACES, LANGUAGES...
}

Nádia Régia Maffi Neckel (UNISSUL) ${ }^{1}$

Resumo: Este texto propõe-se a refletir sobre a materialização das diferentes posições sujeito frente à leitura de parte do acervo do Fundo Documental Neusa Carson, do Laboratório Corpus, da Universidade Federal de Santa Maria/RS. O objetivo destas reflexões é pensar uma proposta de curadoria para uma futura exposição de parte do acervo desse Fundo Documental. Para tanto, busca-se aporte teórico, principalmente, em Orlandi (1984; 2007), Pêcheux (1997; 1999), Le Goff (2003), Sousa (2011) e Neckel (2010). Pretende-se compreender os diferentes modos de inscrição do/no arquivo, assim como possíveis gestos de leitura que se tecem a partir de diferentes recortes.

Palavras-chave: arquivo; posição sujeito; Neusa Carson.

Abstract: The aim of this text is to reflect on the materialization of the distinct subject positions in relation to the reading of part of the heritage of the Documental Trust Neusa Carson of the Laboratório Corpus, at Universidade Federal de Santa Maria/RS. This paper, theoretically anchored on Orlandi (1984; 2007), Pêcheux (1997; 1999), Le Goff (2003), Sousa (2011) and Neckel (2010), discusses a proposal of a curatorship for a future exhibition of the Trust heritage. The study intends to understand the diverse ways of inscription of/on the archive as possible reading gestures that are woven from distinct clippings.

Keywords: archive; subject position; Neusa Carson.

\section{Introdução}

A proposição que me foi feita para integrar uma equipe de elaboração do projeto da primeira exposição de parte do acervo do Fundo Documental Neusa Carson (FDNC) trouxe, ao meu cotidiano de pesquisadora (da Análise do Discurso - AD - e da Arte), tanto um desafio quanto uma extrema curiosidade. Desafio por percorrer leituras e experiências de pesquisa de natureza histórica e linguística que requereram saberes a respeito de uma prática de investigação linguística e antropológica bem específicas. Daí a necessidade de recuperar leituras a respeito da História das Ideias Linguísticas no Brasil, linha de pesquisa fundada por Eni Orlandi, na década de 80, cujo objetivo principal era refletir a respeito das tecnologias linguísticas (dicionários e gramáticas) desde o século XVI, a fim de que eu pudesse compreender melhor o percurso de pesquisa de Neusa Carson. E, curiosidade por conhecer melhor essa pesquisadora que, na década de 70, desbravava o extremo norte brasileiro em busca da descrição da cultura e da língua Macuxi².

1 Programa de Pós Graduação em Ciências da Linguagem-PPGCL - UNISUL. E-mail: nadia.neckel@unisul.br

2 Entre os anos de 1974 e 1976, Neusa Carson desenvolveu atividades acadêmicas e realizou pesquisas em Obio State University e em Kansas University, as quais contribuíram para suas 
Temos, em nossa personagem, uma desbravadora que se embrenha nos rincões brasileiros à procura de uma comunidade, sua língua e sua cultura. Discursivamente, é possível pensar nas diferentes posições sujeito assumidas pela pesquisadora, tanto em relação à tribo e ao Brasil, quanto em relação a suas pesquisas, assim como na sua relação (pessoal e profissional) com os Estados Unidos.

Este texto não se coloca como uma reflexão propriamente teórica, e sim como um percurso de leitura e delineamento de ideias ou de possíveis interpretações do Fundo Documental Neusa Carson, ainda em seu processo de proposição curatorial. Nesse sentido, realizarei a leitura de dois materiais: uma produção artística que retrata a pesquisadora e um de seus relatórios de viagem.

\section{Leitura(s) e proposições em curso}

Como já mencionado, a proposição de um projeto curatorial constitui-se sempre em um desafio. Em se tratando do projeto em questão do FDNC, ele, em especial, institui um percurso de leitura por materialidades e formulações de descrição linguística, o qual, em minha trajetória de pesquisa, mostra-se quase como um percurso inverso, já que as materialidades que comumente me proponho a analisar circulam sempre em uma ancoragem predominantemente não verbal, tais como as imagens, a gestualidade e as sonoridades. Assim, para essa proposta curatorial, partiremos de textos verbais em forma de relatórios de pesquisas e produções acadêmicas, mas, nesse contexto, teremos de pensar também em algumas "traduções" sonoras, gestuais e visuais enquanto percurso interativo de leitura para o espaço(s) expositivo(s).

Dessa forma, inscrevo-me como leitora de parte do acervo do fundo documental, a partir de uma filiação teórica da $\mathrm{AD}$ de linha pecheutiana, buscando compreender as diferentes posições sujeito de nossa personagem, nas textualidades produzidas por ela, para ela ou a partir dela. Com isso, viso a, quiçá, chegar, juntamente com a equipe de curadoria, a uma textualidade visual materializada em forma de uma proposta curatorial para a primeira exposição do Fundo Documental Neusa Carson.

Minha forma de compreender a curadoria compactua da formulação de Sapienza (2006, p. 7), quando este nos afirma que: “O conceito de curadoria

publicações futuras, como a monografia escrita para a obtenção do título de Master of Philosophy, intitulada The problem of classification of South American indian languages e, inclusive, para sua tese de doutorado, intitulada Phonology and Morpho-Syntax of Macuxi (Caribe). A partir desta, Carson adentrou no campo de estudos em descrição de línguas, trabalhando com a descrição da língua indígena Macuxi, no Estado de Roraima. Fonte: <http://corpus.ufsm.br/?page_id=960>. Acesso em: 20 mar. 2013. 
é entendido como uma interferência ativa na exposição, já que envolve a ideia de recorte, gesto do impulso curatorial, que faz a transição do trabalho de artistas até a ocupação do espaço expositivo". Nessa medida, a proposta curatorial se constitui, também, em um gesto de leitura. Por isso, vejo, aqui, uma relação entre o conceito de curadoria como recorte e a proposição teórica de Orlandi (1984) a respeito do recorte. Segundo a autora, o "recorte é uma unidade discursiva. Por unidade discursiva entendemos fragmentos correlacionados de linguagem-e-situação. Assim, um recorte é um fragmento da situação discursiva” (Ibid., p.14). Tal deslocamento é importante, pois não se trata do fragmento em si mesmo, e sim da relação, do laço social no discurso.

É preciso considerar que um "arquivo" também se constitui de recortes, recortes de memórias discursivas. Penso que a noção de recorte é importante aos nos lançarmos à leitura do FDNC. Afinal, é a partir dessa noção que pretendo lançar-me à leitura desse acervo, tomando-o enquanto materialidade discursiva em seu possível gesto de leitura ou possíveis gestos de leitura a serem propostos pelo projeto curatorial da exposição.

Acredito que todo gesto analítico, na perspectiva discursiva, requer sintonia entre o dispositivo teórico e o dispositivo analítico. Nesse sentido, proponho um breve percurso teórico por formulações discursivas que sustentarão tanto nosso movimento de análise quanto, futuramente, nossa proposta curatorial.

\section{Percurso teórico: gestos de/em leitura(s)}

Retomo, aqui, um conceito que é pertinente ao procedimento discursivo que pretendemos discutir, qual seja, o conceito de "modalidades das tomadas de posição". Essas modalidades se dão no interior do lugar de interpretação, afetado tanto pelo interdiscurso como pelo intradiscurso, o que marca um desdobramento do sujeito.

A primeira modalidade a que Pêcheux se refere remete ao que designou de superposição entre o sujeito do discurso e o sujeito universal, ou seja, tal superposição revela uma identificação plena do sujeito do discurso com a forma-sujeito da FD que afeta o sujeito, a qual marca a reduplicaşão da identificação e, por conseguinte, o retorno ao mesmo, "de modo que a 'tomada de posição' do sujeito realiza seu assujeitamento sob a forma do 'livre consentimento': essa superposição caracteriza o discurso do 'bom sujeito"'. A segunda modalidade caracteriza o mau sujeito, discurso em que o sujeito do discurso, através de uma tomada de posição se contrapõe ao sujeito universal, vale dizer, à forma-sujeito. Essa segunda modalidade, ao contrário da primeira, consiste em "uma separação (distanciamento, dúvida, questionamento, contestação, revolta...)" (INDURSKY, 2000, p. 72, grifos da autora). 
Minha leitura a respeito dessas "modalidades de tomadas de posição" é a de que tais modalidades só são possíveis porque o lugar e o momento de interpretação são constituídos a partir de relações entre o espaço social, a memória histórica e a ideologia. Por isso, um discurso é uma constante desestruturação e reestruturação. Advém daí, como nos ensina Orlandi, a "errância de sujeitos e sentidos".

Compreendo, a partir de Michel Pêcheux, que as questões do sujeito e do sentido são determinadas pelo histórico, pelo ideológico e pelo social, ou seja, tratam-se do político na linguagem. Tal postura ultrapassa a posição de entender a linguagem apenas em sua forma (estrutura) e vai ao encontro da compreensão da linguagem no movimento, no confronto, na contradição, na falha, em seu curso, Estrutura e acontecimento.

Se, para Pêcheux (1997), o acontecimento discursivo é o encontro de uma memória com uma atualidade, pensarmos, aí, a ordem discursiva, na ruptura, no estranhamento, na contradição e na falha, faz com que nosso gesto de leitura escape ao logicamente estabilizado e coloque-se no movimento de sujeitos e sentidos na errância do significar.

Nas palavras de Orlandi, discurso é unidade e dispersão: "As relações de linguagem são relações de sujeitos e de sentidos e seus efeitos são múltiplos. Daí a definição de discurso: o discurso é efeito de sentidos entre interlocutores" (2007, p. 21).

É entre os efeitos de sentido e as posições sujeito que me aproximo do FDNC como leitora e, para tanto, recorto do arquivo dois materiais: o primeiro refere-se à imagem de uma produção artística em bico de pena que retrata a pesquisadora Neusa Carson; o segundo refere-se a fragmentos enunciativos de um dos textos da pesquisadora, intitulado Preservação da Lingua e cultura entre os Macuxi (Caribe), um texto datilografado e repleto de marcas "corretivas" realizadas pela própria Neusa Carson.

Inicio pela imagem (Figura 1) da pesquisadora, retratada pelo artista plástico Amoretti ${ }^{3}$ em 1987.

\footnotetext{
${ }^{3}$ Juan Humberto Torres Amoretti (1946) é formado pela Escola Superior de Belas Artes do Peru (Escola Nacional Autônoma de Belas Artes, em Lima, no Peru). É professor aposentado do Centro de Artes e Letras (CAL) da UFSM e artista plástico. São de sua autoria vários monumentos distribuídos no campus dessa universidade. Entre suas produções artísticas, vincula-se também uma série de retratos de santa-marienses, entre eles, o de Neusa Carson.
} 


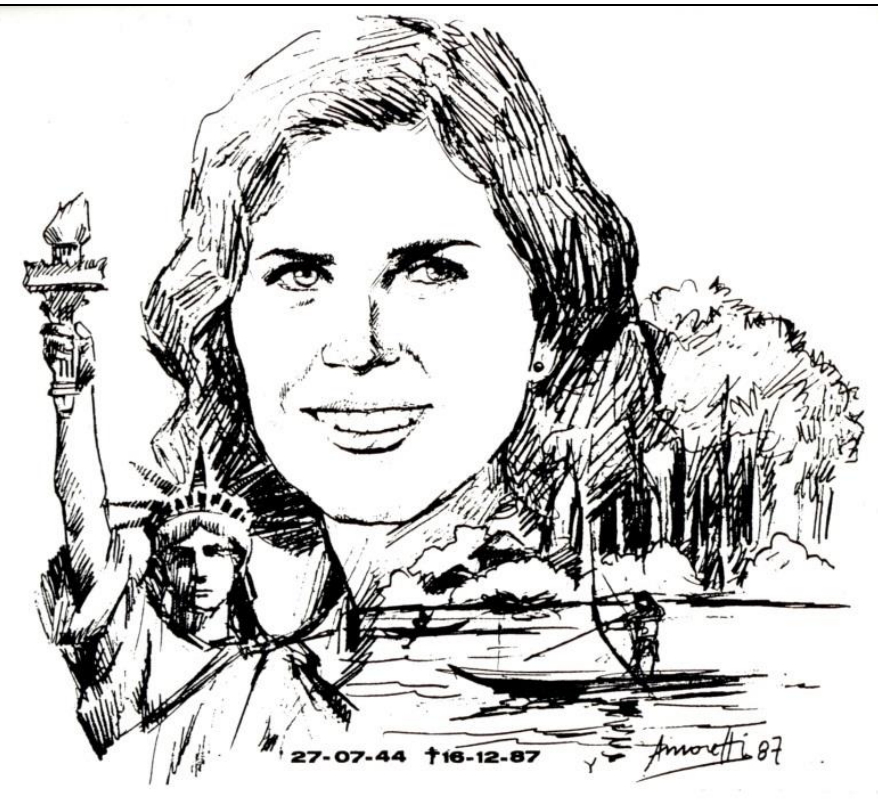

Figura 1 - Lembrança de Neusa Carson desenhada em bico de pena, por Juan Amoretti, em $1987^{4}$. Fonte: Acervo do Fundo Documental Neusa Carson - Laboratório CORPUS - UFSM/RS.

Vejo na imagem não apenas as marcas de modalidades das diferentes posições sujeito, mas também diferentes posições de leitura sobre Neusa Carson. Essas diferentes leituras remetem tanto ao artista que a retratou, uma vez que ele não refere apenas à pessoa, mas aos espaços discursivos de sua incrição; quanto às posições da própria Neusa em seu histórico enquanto pesquisadora.

As diferentes formas de representação do sujeito constituem, para a $\mathrm{AD}$, uma de suas questões centrais. Por isso, compreendemos o gesto de interpretação sempre em movimento, uma vez que o mesmo sujeito pode assumir diferentes posições em uma mesma formação discursiva, assim como quando temos, por exemplo, a leitura de uma imagem pela outra. Vemos funcionando, aqui, a policromia discursiva, que, nas palavras de Tânia Clemente de Sousa, se trata do "gesto que permite, ao interpretar uma imagem, projetar outras imagens, cuja materialidade não é da ordem da

\footnotetext{
${ }^{4}$ Hugo Carson (filho da pesquisadora), em depoimento às arquivistas do FDNC, no Laboratório Corpus UFSM, informou que tal imagem fora distribuída como lembrança por ocasião do funeral de sua mãe, Neusa Carson.
} 
visibilidade, mas da ordem do simbólico e do ideológico" (2011, p. 390). Lembro, nessa esteira, do mestre Pêcheux, que no texto Papel da Memória, já nos alertava sobre como operar com a imagem na $\mathrm{AD}$, "não mais a imagem legível na transparência, por que um discurso a atravessa e a constitui, mas a imagem opaca e muda, quer dizer, aquela da qual a memória "perdeu" o trajeto de leitura." (PÊCHEUX, 1999, p. 55).

Desta forma, quando falamos de expectação e ou produção da imagem, falamos de leitura. E, se falamos de leitura, falamos em gesto de leitura e em gesto de interpretação, ou seja, operamos num nível simbólico. Chama-nos a atenção a palavra "gesto"5 que, na perspectiva discursiva, é diferente da concepção de "ato" derivada da perspectiva pragmática.

Dito de outro modo, o gesto de interpretação só é possível porque se dá no espaço simbólico, que é marcado pela incompletude e pela determinação das condições de produção. Será sempre um gesto por outro. Temos, já aí, o indivíduo interpelado pelo simbólico, pela ideologia, individualizado pelo Estado, por meio de seu funcionamento e suas instituições. O sujeito é interpretado pela história (Cf. ORLANDI, 2004) e não passa por ela isento de suas marcas.

Assim, na tecedura ${ }^{6}$ das imagens, recuperamos outras tantas imagens que se projetam enquanto monumento. Ao recuperarmos apenas o rosto da pesquisadora projetado em primeiro plano, imediatamente nossa memória cola em outra imagem: a imagem do monumento estadunidense do Monte Rushmore, de Dakota do Sul (famoso em filmes hollywoodianos, no qual foram esculpidas as faces de quatro presidentes americanos, a saber: George Washington, Thomas Jefferson, Theodore Roosevelt e Abraham Lincoln), a partir de um movimento de leitura de uma imagem pela outra. Imagens como representação, pessoas-monumentos. Nesse sentido, temos uma recuperação teórica importante para fazermos aqui. Se retomarmos a leitura do historiador Jacques Le Goff, a partir das noções de documento e monumento, teremos, em suas palavras:

A palavra latina monumentum remete para raiz indo-europeia mem que exprime uma das funções essenciais do espírito (mens), a memória (memini). O verbo monere significa 'fazer recordar', de onde 'avisar', 'iluminar', 'instruir'. O

\footnotetext{
${ }^{5} \mathrm{O}$ gesto de interpretação, fora da história, não é formulação (é fórmula), não é re-significação (é rearranjo). Isto não quer dizer que não haja produção de autoria. Pelo contrário, há, mas de outra qualidade, de outra natureza, porque a natureza da materialidade da memória é outra. E, como sabemos, em discurso, distintas materialidades sempre determinam diferenças nos processos de significação (ORLANDI, 2004).

${ }^{6}$ A noção de tecedura foi cunhada a partir da imagem metafórica de uma teia, numa teia invisível que nos envolve por completo. E, é nessa teia que somos tecidos discursivamente. No caso da imagem, Tecedura representa a rede de filiações da memória a outras imagens e/ou materialidades, às quais nem sempre temos acesso, pois tal teia é tramada pelos esquecimentos constitutivos (1 e 2) formulados por Pêcheux (NECKEL, 2010).
} 


\begin{abstract}
monumentum é um sinal do passado. Atendendo às origens filológicas, o monumento é tudo aquilo que pode evocar o passado, perpetuar a recordação, por exemplo, os atos escritos. Quando Cícero fala dos monumenta buius ordinis [Philippicae, XIV, 41], designa os atos comemorativos, quer dizer, os decretos do senado, mas, desde a Antiguidade romana, o monumentum tende a especializar-se em dois sentidos: 1) uma obra comemorativa de arquitetura ou de escultura: arco de triunfo, coluna, troféu, pórtico, etc.; 2) um monumento funerário destinado a perpetuar a recordação de uma pessoa no domínio em que a memória é particularmente valorizada: a morte (LE GOFF, 2003, p. 535).
\end{abstract}

Quando nos voltamos à leitura dessa imagem, nas condições de produção que lhe são próprias - memória/homenagem/memória de Neusa Carson -, podemos afirmar que já não temos mais apenas a imagem como representação, e sim como marca de diferentes posições sujeito. Considerando suas condições de produção, também temos a imagem tanto no movimento de monumentação da posição de Neusa, enquanto pesquisadora, quanto como documento, ao retornarmos a ela, enquanto arquivo de sua trajetória disposto como parte do acervo do FDNC.

Se pensarmos nas "modalidades da tomada de posição", as quais nos referimos no início do texto, é possivel afirmarmos que essa imagem, por um lado, marca uma leitura da pesquisadora Neusa Carson. Enquanto uma tomada de posição, retomo a leitura de Pêcheux feita por Indursky (2000) para afirmar que "a 'tomada de posição' do sujeito realiza seu assujeitamento sob a forma do 'livre consentimento': essa superposição caracteriza o discurso do 'bom sujeito" ao centralizar a imagem do rosto de Neusa Carson. Por outro lado, marca também uma segunda modalidade, aquela que "caracteriza o 'mau sujeito', discurso em que o sujeito do discurso, através de uma 'tomada de posição', se contrapõe ao sujeito universal, vale dizer, à forma-sujeito" (Ibid.). Isso porque temos uma posição sujeito na intersecção de duas posições possíveis: uma inscrevendo-a no contexto norte americano, e outra, em meio à Floresta Amazônica e aos seus habitantes indígenas.

Assim, em termos compositivos, a imagem divide-se em três composições distintas: 1) a estátua da liberdade; 2) a fotografia de Neusa Carson; e 3) a paisagem da floresta, do rio e os índios em suas canoas.

Se continuarmos o percurso do olhar por estas três composições da imagem, temos materializadas pelo menos três posições distintas: a norteamericana, a brasileira e a Macuxi. É interessante percorrer, pelo olhar, tal imagem, tão atravessada por discursos que se sustentam na contradição. $\mathrm{Na}$ contradição própria do(s) discurso(s) em seu movimento de estruturação e desestruturação.

Por sua composição triádica, a imagem materializa o sujeito cindido e os sentidos em movimento. Um sujeito cindido que, nas palavras de Orlandi, se constitui na e pela linguagem, uma linguagem que só faz sentido porque se inscreve na história $(2005$, p. 25). 
Assim, a tessitura ${ }^{7}$ da imagem em sua composição triangular e traços em preto e branco nos leva a teceduras complexas de diferentes posições: a acadêmica, a pesquisadora, a política e a pessoal. São três imagens distintas que formam essa imagem em seu efeito de unicidade. Tal como as diferentes posições do sujeito do discurso, é o múltiplo que, em uma determinada estruturação, produz o efeito de unidade.

Do lado esquerdo, como parte do primeiro plano, temos um fragmento da Estátua da Liberdade, sua coroa e tocha. Estátua inaugurada em 1886 (presente francês aos EUA) e considerada ícone norte americano. Uma inscrição nesse monumento parece ecoar em sua imagem e sedimentá-la como um símbolo de coragem e promessa de liberdade: "Venham a mim as massas exaustas, pobres e confusas ansiando por respirar liberdade. Venham a mim os desabrigados, os que estão sob a tempestade. Eu os guio com minha tocha"8. Apesar de retratada apenas em parte, a estátua já transporta seus principais símbolos: o braço levantado, a tocha e a coroa. Dessa forma, mesmo que pela imagem não tenhamos acesso à sua inscrição, ainda assim esses sentidos ressoam no pequeno fragmento de imagem. O olhar da estátua, sempre avante, faz com que todos nós, leitores dessa imagem, sejamos um pouco dessa massa de desabrigados. Ela nos "empurra" a esse lugar, sem nenhuma espécie de negociação.

Porém, esses olhares presentes na relação de interlocução, se relacionados com o olhar do leitor, que, em percurso, desliza na superfície da imagem, eles correm para o olhar centralizado da personagem retratada ao centro. Temos, então, olhares em direção opostas, olhares que se constituem na contradição: o olhar da estátua da liberdade, o olhar de Neusa Carson, mas não o olhar do índio. O olhar de Neusa Carson é o vértice superior dessa triangulação de olhares e, dessa triangulação de posições, constitui-se em um olhar que se divide entre o já legitimado e aquilo que não tem legitimação.

Se recuperarmos o cenário da política internacional da década de 70 , entre o "Primeiro Mundo" (EUA) e um lugar qualquer, o de um "País Subdesenvolvido" (Brasil), em plena ditadura militar, podemos dizer que havia muitas coisas que não galgavam a legitimação. É desse lugar de divisões e contradições que Neusa Carson vai percorrendo seu caminho de pesquisadora, na área de Linguística, a partir da prática de "descrição" da língua Macuxi.

\footnotetext{
7 A noção de tessitura trata da estrutura da própria linguagem, nas diferentes materialidades discursivas ancoradas no artístico, em seus modos de funcionamento. Tomamos metaforicamente tessitura do conceito de funcionamento musical, como aquilo que ordena o andamento, os compassos, as notas, etc. Assim como no funcionamento musical, a tessitura estaria para a estrutura do dizer (visual/sonoro/gestual/verbal). Ela se mostra na circulação do movimento parafrástico, o que recuperaria uma memória marcada e mostrada pela heterogeneidade discursiva (cf. NECKEL, 2010).

${ }^{8}$ Disponível em: <http://www.formadoresdeopiniao.com.br>. Acesso em: 20 mar. 2013.
} 
Mas, como uma língua não é somente estrutura, não é sequer Uma Lingua, são línguas, lugares de inscrição, posições, laços sociais. Neusa Carson vai registrando fios dessa complexidade nos relatórios (diários de viagem), textos e gravações que realiza junto aos Macuxi, em Roraima.

A minha porta de entrada para os materiais que analiso, na maioria das vezes, é pela imagem, e foi olhando para esse desenho que me interroguei sobre o percurso dessa pesquisadora. Isso me levou aos textos, em especial, ao que descreve a cultura e a língua Macuxi (também chamado de Diário de Viagem), intitulado Preservação da Lingua e Cultura entre os Macuxi (Caribe). A partir desse texto é que, por meio de alguns de seus enunciados, busco compreender: o que marca, assim como a imagem, posições sujeito diferentes?

Para isso, é necessário considerar que:

O sujeito se constitui pelo "esquecimento" daquilo que o determina. Podemos agora precisar que a interpelação do indivíduo em sujeito de seu discurso se efetua pela identificação (do sujeito) com a formação discursiva que o domina (isto é, na qual ele é constituído como sujeito): essa identificação, fundadora da unidade (imaginária) do sujeito, apoia-se no fato de que os elementos do interdiscurso (sob sua dupla forma, descrita mais acima, enquanto "préconstruído" e "processo de sustentação") que constituem, no discurso do sujeito, os traços daquilo que o determina, são reinscritos no discurso do próprio sujeito (PÊCHEUX, 1997, p. 163, grifos do autor).

O efeito de unicidade dos sujeitos e do sentido é um movimento próprio do discurso. Tanto na imagem que retrata Neusa Carson quando no texto produzido pela pesquisadora a respeito da cultura Macuxi, esse efeito de unicidade deixa suas marcas. Apresentarei, a seguir, apenas dois fragmentos do texto e das observações, feitas, à mão, por Neusa Carson, em um dos primeiros movimentos de "descrição" da cultura e língua Macuxi.

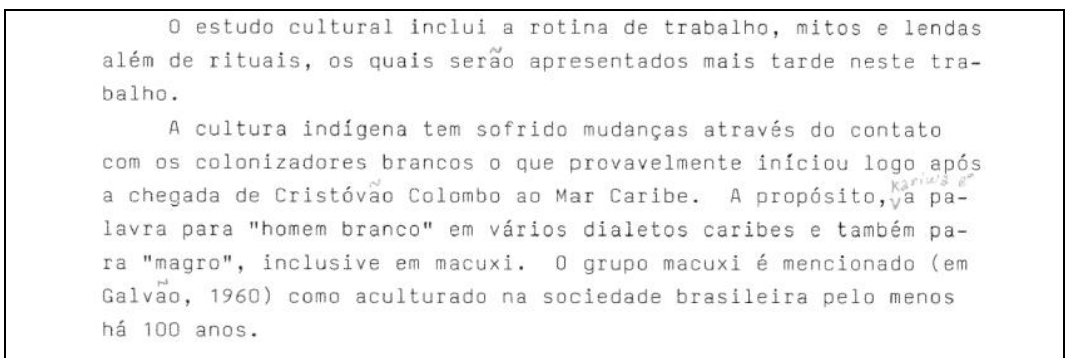

Figura 2 - Fragmento 01 - Página 01 do Diário - Preservação da Lingua e Cultura entre os Macuxi (Caribe). Fonte: Acervo do Fundo Documental Neusa Carson - Laboratório CORPUS $\mathrm{UFSM} / \mathrm{RS}$. 


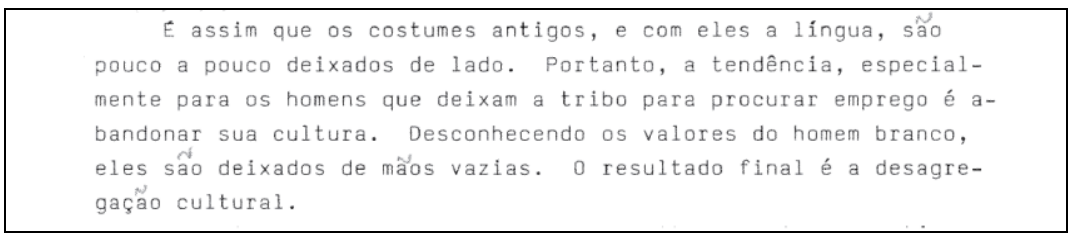

Figura 3 - Fragmento 02 - Página 05 do Diário - Preservação da Lingua e Cultura entre os Macuxi

(Caribe). Fonte: Acervo do Fundo Documental Neusa Carson - Laboratório CORPUS $\mathrm{UFSM} / \mathrm{RS}$.

Não me deterei aqui em uma análise aprofundada de tais passagens, até porque seria prematuro de minha parte tomar tais enunciados isoladamente sem considerar o arquivo do FDNC como um todo, em suas condições de produção. Contento-me apenas em uma rápida relação entre a produção artística anteriormente apresentada e esses dois pequenos fragmentos. Em minha leitura, tais enunciados marcam, cada um em sua medida, o olhar de Neusa Carson sobre o Macuxi.

É preciso considerar que, entre as décadas de 60 e 70 , a relação estreita entre a Antropologia e a Linguística suscitava, nos trabalhos dos pesquisadores, uma preocupação e uma atenção aos aspectos culturais como um todo a respeito da comunidade linguística pesquisada. Tal postura ecoa nos trabalhos de Neusa Carson.

Sob esse aspecto, apesar de sua "tarefa" ser a da descrição linguística Macuxi, era impossível fechar os olhos às imagens, aos mitos e aos rituais, às danças, aos sons, às cores, à culinária e a tudo mais que envolvia a vida nessa comunidade.

Pelos fragmentos expostos nas formas de Figuras 2 e 3, vejo que era impossível à pesquisadora não atentar também aos aspectos e às implicações políticas dessa relação homem branco versus índio. No primeiro fragmento, temos as expressões: "cultura" e "aculturado"; já no segundo fragmento, temos "desagregação cultural".

Tais expressões materializam fortemente a dominância de formações discursivas do dito "primeiro mundo" sob "países subdesenvolvidos". Tomo essas passagens como uma paráfrase da imagem apresentada em suas três composições. Tanto na leitura do artista sobre Neusa Carson quanto na leitura de Neusa Carson sobre o Macuxi, o referido confronto é textualizado.

Mariani tece uma importante observação em seu trabalho a respeito da política de sentidos das línguas e as políticas linguísticas, que me parece ser muito pertinente a essas duas leituras "sobre" língua/cultura/sujeito, realizadas tanto por Amoretti quanto por Neusa Carson:

[...] o simples falar ou tomar a palavra é em si uma prática política, como todas as suas implicações. $O$ fato de tomar a palavra, o colocar-se como enunciador num dado contexto histórico-social, é algo que instaura diferenças, mesmo 
quando se busca o consenso. Usar uma palavra é não usar outra, é fazer recortes em regiões de sentidos sem ter nenhuma garantia de um entendimento absoluto, é inscrever-se em redes de filiações de sentidos, as memórias e esquecimentos constitutivos do dizer. Falar é inscrever-se em redes históricas e sociais de produções de sentidos que antecedem ao próprio ato em si, e cuja memória nem sempre se depreende com nitidez. Não há, desse ponto de vista, um total domínio sobre o que se diz, embora haja uma perene e ilusória tentativa de controle do dizer (MARIANI, 2004, p. 40).

Ao retratar a pesquisadora entre "dois mundos", porém com um olhar interessado ao índio e à natureza integradora de seu ambiente, o artista marca essa posição política, posição essa tanto sua (a do artista) quanto da própria personagem retratada. Neusa Carson, por sua vez, também assume uma posição, ao preocupar-se, em seu texto-diário, com o cenário político da colonização linguística/cultural.

Se pelo significar (seja pela palavra, imagem ou som) o sujeito assume posições, então a linguagem é, por natureza, política. Assim, nesses pequenos fragmentos do nosso recorte, marcamos as diferentes posições do sujeito e de suas leituras (na imagem e na palavra). Compreendemos, no entanto, que, na extensão do seu acervo, o FDNC marca uma série de outras posições teóricas, políticas e históricas que circulam nesses dizeres.

\section{Considerações provisórias}

Tomar um percurso é sempre tomar percursos. Construir um arquivo é sempre percorrer arquivos outros. Falar "uma palavra" é não falar outras tantas. Produzir uma imagem é ancorar-se em tantas outras imagens, às quais nem sempre temos acesso, e eleger, entre tantos traços possíveis, apenas alguns que possam representar, e que, por sua vez, consigam materializar posições nem sempre "pensadas", mas possíveis. Construir, a partir de um arquivo, uma exposição que materialize visual e sinestesicamente um percurso é aceitar-se sempre no movimento de sentidos e sujeitos.

Discursivamente, somos determinados pelas "modalidades das tomadas de posição" que se dão no interior do lugar de interpretação. Assim, nosso gesto de interpretação será sempre afetado tanto pelo interdiscurso como pelo intradiscurso, marcando sempre um desdobramento do sujeito. Isso é incontornável ao sujeito e ao sentido.

Haverá sempre recortes; por isso, toda proposta curatorial constitui um recorte de arquivo, o arquivo enquanto um recorte da memória e o sujeito enquanto um recorte do sentido. Assim, penso que uma proposta curatorial apropriada para o FDNC poderá partir de imagens, sonoridades, mapas, depoimentos e dos relatos da própria Neusa Carson, buscando compreender como tais materialidades podem marcar diferentes posições sujeito de Neusa, frente à sua pesquisa, tornando-se parte política dela. 


\section{REFERÊNCIAS}

CARSON, Neusa. Preservação da Língua e Cultura entre os Macuxi (Caribe). In: Fundo Documental Neusa Carson - Laboratório Corpus Universidade Federal de Santa Maria/RS. Disponível em: http://corpus.ufsm.br/?page_id=960. Acesso em: 20 mar. 2013. INDURSKY, Freda; CAMPOS, Maria do Carmo (Org.). Discurso, memória, identidade. Porto Alegre, RS: Sagra Luzzatto, 2000.

LE GOFF, J. História e memória. Traduzido por: Bernardo Leitão et al. 5 ed. Campinas, SP: Editora da UNICAMP, 2003.

MARIANI, Bethania Colonização Linguística. Campinas, SP: Pontes, 2004. NECKEL, Nádia Régia Maffi. Tessitura e tecedura: movimentos de compreensão do Discurso Artístico no audiovisual. Tese (Doutorado) Programa de Pós-Graduação em Linguística do Instituto de Estudos da Linguagem da UNICAMP, Campinas/SP, 2010.

ORLANDI, Eni Puccinelli. Segmentar ou recortar? Linguística: questões e controvérsias. Uberaba, Série Estudos 10. Curso de Letras do Centro de Ciências Humanas e Letras das Faculdades Integradas de Uberaba, p. 9-27, 1984.

. Cidade dos Sentidos. Campinas, SP: Pontes, 2004.

Análise de Discurso: princípios e procedimentos. 6. ed. Campinas, SP: Pontes, 2005.

. Sujeito discursivo contemporâneo: um exemplo. In: INDURSKY, F.;

FERREIRA, C. Análise do Discurso no Brasil: mapeando conceitos, confrontando limites. São Carlos, SP: Clara Luz, 2007.

PÊCHEUX, Michel Discurso: Estrutura ou acontecimento. Traduzido por: Eni Puccinelli Orlandi. São Paulo: Pontes, 1997.

. et al. Papel de Memória. Traduzido por: José Horta Nunes. Campinas, SP: Pontes, 1999.

SAPIENZA, Tarcísio Tatit. Crítica e curadoria nas artes plásticas. DVDteca Arte na Escola - Material Educativo para professor-propositor. (coord. Mirian Celeste Martins e Gisa Picosque). São Paulo: Instituto Arte na Escola, 2006.

SOUZA, Tânia Conceição Clemente de Souza. Imagem, textualidade e materialidade discursiva. In: RODRIGUES et al. Análise de Discurso no Brasil: Pensando o impensado sempre, uma homenagem a Eni Orlandi. Campinas, SP: RG, 2011. 